\title{
REFLECTIONS
}

\section{Sí, Doctora}

Lucy M. Candib, MD

Department of Family Medicine and Community Health, University of Massachusetts Medical School and Family Health Center of Worcester, Worcester, Mass
Conflicts of interest: none reported

\section{CORRESPONDING AUTHOR}

Lucy M. Candib, MD

Family Health Center of Worcester

26 Queen St.

Worcester, MA 01610

lcandib@massmed.edu

\begin{abstract}
Experience with seeing Latino patients at a community health center has taught a family physician that the patient's response, "Sí, doctora [Yes, doctor]" can have multiple meanings. Patients might say "yes" during consultations to avoid conflict or to defer to the more powerful doctor. The clinician's understanding had to move to deeper levels when a visiting Ecuadorian friend learning English used "yes" multiple times in conversation, but not as an indicator of agreement or even comprehension. The family doctor realized that she could not assume what the patient implies by this simple expression. The apparent agreement of "yes" requires more. When a patient says, "Sí, doctora," the doctor must probe with more questions and listen hard to the answers.
\end{abstract}

Ann Fam Med 2006;4:460-462. DOI: 10.1370/afm.572.

\section{INTRODUCTION}

Tinish speaking and await my patient's response. She nods and says, "Sí, doctora." What does this mean? Over the years of seeing Latino patients in my workable but not entirely grammatical Spanish, I have come to understand that patients will often say "yes" to me when they do not necessarily mean either that they agree with me or that they will do what I have recommended. As have many other doctors, I have come to see this "yes" response as an occupational hazard. Its meaning is opaque. If I do not get it right, I could be hopelessly mired in misperceptions for weeks, months, or longer.

"Sí, doctora" could mean "Yes, I agree with your plan and I will do what you recommend." This interpretation views these words as the hoped-for agreement on common ground.1 Too often we take this meaning to be correct and go no further. Often, however, "Sí, doctora" means "I have heard what you are saying but I don't really want to do that; I also don't want to be rude and disagree with you openly." Left unexplored, "Sí, doctora" with this meaning leads to deep miscommunication. The patient, for whatever reason, does not feel that explicit disagreement is tolerable. Perhaps cultural style might lead a patient to hope for a more indirect way to indicate dissent without being overt. The patient may fear that open disagreement or blunt refusal might make the doctor angry or frustrated. (English-speaking patients may share the same anxieties, but on the whole they are less likely to use the deferent-sounding phrase "Yes, doctor" as frequently as Spanish-speakers.) Fear of disruption of the relationship might lead the patient to assent verbally while not truly being in agreement. This conflict-avoidant posture may derive from the multiple layers of power discrepancy (class, education, expertise, to name a few) in the doctor-patient relationship between a North American doctor and a Latino patient. However democratic I may wish to be in principle, the patient recognizes the implied and (sometimes actual) power of my position, and acquiesces: "Sí, doctora." However much I may struggle against $\mathrm{it}_{,}{ }^{2}$ the power difference between doctor and patient is a reality that the patient accepts using these 2 simple words.

My cultural and political interpretation of "Sí, doctora" had not 
changed much in the last 10 years since our return from a year-long stay in Ecuador until our friend Raul came to stay in our home for 2 months to have an intensive experience in English immersion. Since 1995, Richard, my spouse, and I have been friends with Raul, who had originally trained as a family doctor. Now he works for the United Nations in the office of the World Food Programme in Quito; he is in charge of emergency responses to disasters in parts of Latin America and the Caribbean. Learning English would enable Raul to play a role in the World Food Programme beyond Latin America and become a more effective leader within the United Nations.

Promising never to speak Spanish, Richard and I eagerly invited Raul to stay with us during his English immersion. He had, after all, offered us unfailing hospitality as well as innumerable Spanish grammar lessons during the past 10 years. We planned a variety of introductions, classes, and social events designed to enable him to meet new people and speak English for hours every day. Of course, we, too, were involved in his English grammar instruction. When I came home from work one evening after Raul had been with us for 10 days, Richard confided to me in private that it had been a hard day. He had "lost it" with Raul.

"He keeps nodding and saying, 'Yes, yes,' and then he asks a question that shows he doesn't understand a word I am saying. I finally yelled at him and told him to stop saying 'Yes' and tell me if he didn't understand."

Richard, a lifelong teacher, obviously felt ashamed of himself for losing his temper. And losing it with his friend, whom he loves dearly, felt like a failure of generosity. Suddenly the enormous chasm of language and nonverbal behavior between cultures had opened up between 2 fast friends. Here again was the "Sí, doctora" problem, but this time it was not a poorly educated rural Latina from a developing country, nor was it an undocumented immigrant dependent on Free Care; it was our friend Raul, family doctor, UN official, emergency specialist, who was saying "yes" when he just didn't understand.

Breaking our promises to speak only English, we had long talks in Spanish with Raul about the meaning of "yes." I reiterated my various theories about conflict avoidance and power differentials in relationships as underlying reasons for "yes" from patients, but I came up puzzled by what it meant from Raul. He put forth the possibility that the listener, in this case, himself, nods and says "yes" when he is taking in information, but that these signals do not confer understanding or agreement and do not imply that the listener has taken in enough information to make a decision. I would add to this definition, now, after more hours of observation, that "yes" may also be a way to get the speaker to keep talking when the listener does not fully understand: "I am not certain of what you just said, and I hope if you keep talking, I will hear more familiar words and understand what you mean." (This interpretation is the opposite of the speaker's usual assumption - that "yes" implies understanding.) Here, "yes" would be typical of back channel responses, "verbal markers of continued attention uttered by the listener: examples from English include such verbal acts as ' $\mathrm{hmm}$ ', 'OK' and 'right.' These serve as verbal indicators of sustained attention and encouragement emitted by the person who does not hold the speaking floor." ${ }^{\prime 3}$ Alternatively, Raul's "yes" could also be an example of what linguists call a dialogic behavior related to taking turns in the conversation. ${ }^{4}$ Raul's "yes" punctuates the interchange, telling Richard that in lieu of taking the floor, Raul wants him to keep talking. In either case, these responses, like "uh huh" in English, may imply understanding, but clearly not necessarily so.

Back channel responses may be more common in conversational exchanges for certain cultures; for instance, Japanese doctors and patients use them far more frequently than US doctors and patients. ${ }^{3}$ English and Spanish speakers may use them with equal frequency, but men and women use them differently depending on whether the conversation takes place between single sexes or mixed sexes. ${ }^{5}$ Such studies do not shed light on the multiple meanings that these responses might have, but they begin to point out that power relations between the speakers may affect how such markers are used. We do not know the frequency or meaning of this linguistic response among Spanishspeaking patients of either sex, but our experience with Raul suggests that this cultural linguistic strategy has implications well beyond the walls of the doctor's office.

Raul understands a lot more English now, 2 weeks later, and we can talk together in English about the frustration we each feel in not making ourselves better understood. Richard and I increasingly admire Raul's dogged intensity in mastering our irrational language and grammar. And I, for one, am grateful to him for showing me the limits of my stale understanding of the meaning of "yes." While Raul's "yes" may have meant, "Yes, I am listening," the nods and yesses of apparent agreement from patients can have multiple possible meanings and require more of me. I must probe with more questions and listen hard to the answers that may indicate uncertainty or even reluctant disagreement. These days, when a patient says, "Sí, doctora," I smile inwardly and begin to ask questions all over again. "So how does this seem to you? Can you tell me how you are thinking about what we were just discussing?"

To read or post commentaries in response to this article, see it online at http://www.annfammed.org/cgi/current/full/4/5/460. 
Key words: Communication; cross-cultrual comparison; physicianpatient relations

Submitted November 13, 2005; submitted revised January 3, 2006; accepted February 3, 2006

\section{References}

1. Stewart M, Brown JB, Weston WW, et al, eds. Patient-Centered Medicine: Transforming the Clinical Method. Abingdon, Oxon, UK: Radcliffe Medical Press; 2003.
2. Candib LM. Medicine and the Family: A Feminist Perspective. New York, NY: Basic Books; 1995.

3. Ohtaki S, Ohtaki T, Fetters MD. Doctor-patient communication: a comparison of the USA and Japan. Fam Pract. 2003;20:276-282.

4. Hall JA. Non-Verbal Sex Differences: Communication Accuracy and Expressive Style. Baltimore, Md: Johns Hopkins University Press; 1984.

5. Feke MS. Effects of Native Language and Sex on Back Channel Behavior. In: Sayahi L, Ed. Selected Proceedings from the First Workshop on Spanish Sociolinguistics. Somerville, MA: Cascadilla Proceedings Project;2003:96-106.

\section{Annals of Family Medicine Resident Research Supplement Call for Papers and Reviewers}

The Annals of Family Medicine seeks both research manuscripts and peer reviewers for a supplement devoted to research conducted by family medicine residents. The supplement is sponsored by the American Academy of Family Physicians Foundation.

Volunteer Reviewers. We encourage residents, residency faculty members, and others interested in nurturing resident research to contribute by reviewing 1 to 2 resident manuscripts in their areas of interest and expertise. To volunteer, please e-mail ressupp@musc.edu, giving your: (1) name; (2) role: resident, residency faculty member, or other ${ }_{i}(3)$ methods expertise: quantitative and/or qualitative methods; and (4) interest in reviewing manuscripts on clinical, quality improvement, community, health services, educational, or other research. We will send instructions on how to conduct a helpful peer review.

Submit Manuscripts. Manuscripts must be based on original work conducted while the lead author is/was a resident in a family medicine training program. They must describe original research that contributes new, transportable knowledge (excluding case reports, nonsystematic reviews, or essays). Manuscripts must follow the instructions for authors, available at http://annfammed.org/misc/ifora.shtml. The deadline for submission of manuscripts is March 1, 2007. Those submitted earlier will have priority in the review process.

Submit manuscripts to: ressupp@musc.edu.

Do not submit manuscripts for this supplement directly to the Annals.

Review Process. Guest editors Peter J. Carek, MD, MS, and Arch G. Mainous III, PhD, of the Medical University of South Carolina will coordinate initial peer review by reviewers who volunteer in response to this announcement. Based on this initial review, they will select manuscripts for formal peer review by the Annals. We will invite authors of the selected papers to submit a revised manuscript for possible inclusion in the supplement. The anticipated publication date of the supplement is January 2008. 